\title{
Spatial and temporal control elements of the Drosophila engrailed gene
}

\author{
Judith A. Kassis \\ Laboratory of Cellular and Molecular Biology, Division of Biochemistry and Biophysics, Center for Biologics Evaluation and \\ Research, Food and Drug Administration, Bethesda, Maryland 20892 USA
}

\begin{abstract}
engrailed (en) is a segmentation gene expressed in a series of stripes throughout embryonic development. Here, I show that regulatory sequences for striped expression are present within the first intron of en. The 1-kb intron is able to confer striped expression early, but not late, in development. This shows that different regulatory sequences are required for en stripes at different times in development. Furthermore, stripes generated by the intron are coincident with en stripes in a wild-type background but behave differently from endogenous engrailed stripes in some segmentation mutant backgrounds. Thus, although the intron can induce apparently normal stripes, it lacks some of the regulatory sequences present within the endogenous gene. These experiments suggest that multiple regulatory programs control en expression in stripes, and each may be able to confer "normal" spatial regulation independently.
\end{abstract}

[Key Words: Regulatory sequences; Drosophila engrailed gene]

Received August 11, 1989; revised version accepted January 3, 1990.

The engrailed (en) gene is 1 of $>20$ zygotic genes important for segmentation of the Drosophila embryo (Jürgens et al. 1984; Nüsslein-Volhard et al. 1984; Wieschaus et al. 1984). These genes are classified into three groups: gap genes, which affect large groups of segments, pairrule genes, which affect pattern elements in every other segment, and segment polarity genes, which affect pattern elements present in every segment (Nüsslein-Volhard and Wieschaus 1980). They act sequentially to subdivide the embryo into progressively finer units during development (for a recent review, see Ingham 1988).

$e n$ has been classified as a segment polarity gene and is expressed early in Drosophila development in a series of stripes that transect the anterior-posterior axis of the ectoderm (DiNardo et al. 1985; Fjose et al. 1985; Kornberg et al. 1985). en stripes are first evident at the cellular blastoderm stage at $\sim 3 \mathrm{hr}$ of development and are maintained at least until $15 \mathrm{hr}$ of development. Genetic experiments have indicated that different genes are required for en stripes at different times in development (DiNardo et al. 1988; Martinez-Arias et al. 1988). The pair-rule genes are thought to initiate en expression in stripes, whereas the activity of segment polarity genes is necessary for maintaining striped expression later in development. Many of the pair-rule genes contain homeo domains and may control en expression directly (DiNardo and O'Farrell 1987; Desplan et al. 1988). In contrast, at least some of the segment polarity genes encode proteins that are thought to be involved in cell-cell communication, and probably do not directly interact with en DNA (Ingham 1988). These data suggest that different regulatory sequences may be required for generating en stripes at different times in development.
To identify important sequences of the en gene, I have been studying its sequence conservation between two distantly related Drosophila species, $D$. virilis and $D$. melanogaster (Kassis et al. 1985; 1986; 1989). Here, I report that sequences within a conserved intron are sufficient to generate stripes that are coincident with en stripes. Further experiments indicate that the intron can induce stripes early, but not late, in development. Comparison of striped expression patterns generated from the intron with those of the endogenous en gene in various segmentation mutants suggests that the intron responds to only some of the genes that regulate en expression. This suggests that there may be multiple mechanisms for generating en stripes. In fact, current data suggest that at least three temporally overlapping, regulatory programs activate en expression in stripes. Other data suggest that multiple mechanisms act to keep en off between stripes. These studies emphasize the dynamic nature of en stripes and hint at the complexity of the control elements involved.

\section{Results}

\section{Expression patterns of en/lacZ fusion genes}

Figure 1 shows the P-element constructions used to generate transgenic flies for these experiments. A 2.6-kb fragment, including the en promoter and 188 bases of en-untranslated leader, was cloned in a vector that produces $\beta$-galactosidase as a marker protein. The $2.6-\mathrm{kb}$ fragment (A in Fig. la) does not direct $\beta$-galactosidase expression in a position-independent manner. Six independent lines were analyzed; in four of the lines, weak 
Kassis

a)

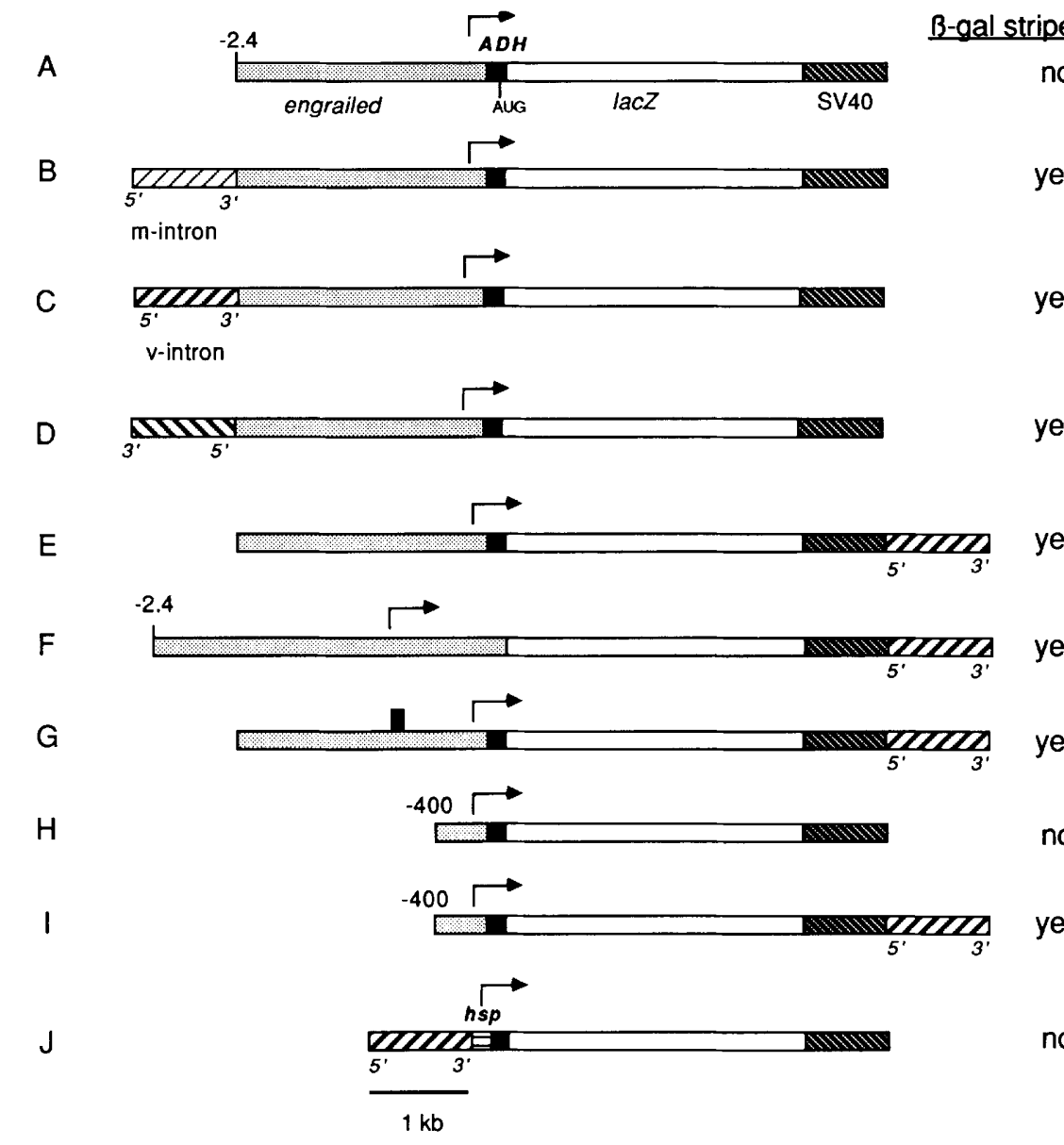

b)

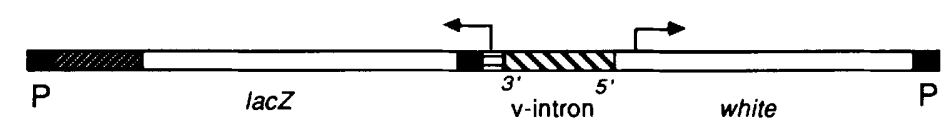

fat body, neurons

no

no

yes

yes

yes

yes

yes

yes

no

yes

yes

white stripes

Figure 1. DNA constructs integrated into the genome by P-element-mediated transformation. (a) A D. melanogaster en fragment (starting at an EcoRI site at -2407 extending through +188 ; shaded boxes) was cloned into the vector pC4ATG $\beta$-gal (Thummel et al. 1988). In this vector, an untranslated leader fusion was made between en (or $h s p 70$ ) and the $D$. melanogaster alcohol dehydrogenase gene ( $\mathrm{ADH}$; black boxes), which provides the start site for translation (AUG). An ADH/ $\beta$-galactosidase fusion protein is made. An SV40 fragment provides the polyadenylation signal. The arrow indicates the start site of transcription from the en (or hsp 70 ) promoter. Intron 1 from either $D$. virilis en (v-intron) or $D$. melanogaster en (m-intron) was cloned either upstream of the EcoRI site or downstream of the SV40 fragment so that it was not within the transcription unit. ( $5^{\prime}$ and $\left.3^{\prime}\right)$ The normal orientation of each intron within the en gene. The two intron fragments used in this study include most of the conserved DNA of this intron. F contains en DNA extending from -2407 to +1099 and expresses an en/ $\beta$-gal fusion protein. In $G$, the black box over the en DNA indicates the approximate location and extent of sequences deleted in this construction. For J, a fragment of the hsp 70 gene (horizontal stripes, from -73 to +70 , obtained from the laboratory of $P$. Wensink) was cloned into pC4ATG $\beta$-gal, and the $D$. virilis intron was cloned upstream. (Right) A summary of the $\beta$-galactosidase protein patterns seen in multiple transgenic lines for each $P$ element construct. (b) The orientation of the lacZ and white genes in construct J. All other lacZ constructs are also in this orientation. The white gene is expressed in stripes from this construct (see Results). Many of the other P-element construct lines (including D and E) also express the white gene in stripes further emphasizing the position and orientation independence of the intron (data not shown).

dorsolateral stripes were seen (data not shown). This weak pattern is generated at many different chromosomal locations in many different P-element vectors that contain a promoter, the reporter gene $\beta$-galactosidase, and no tissue-specific enhancer (Bellin et al. 1989; Ghysen and O'Kane 1989). In addition to this weak basal pattern, most of the lines have unique patterns of $\beta$-galactosidase expression, the nature of which depends on the position of insertion in the genome (data not shown). Thus P-element A acts like previously described "enhancer traps," in which a promoter activity is controlled by nearby genomic enhancers $\left(\mathrm{O}^{\prime}\right.$ Kane and Gehring 1987; Bellin et al. 1989; Bier et al. 1989).

I decided to test for the presence of regulatory DNA within intron 1 of en because a comparison of $D$. melanogaster and $D$. virilis en intron 1 showed islands of con- 

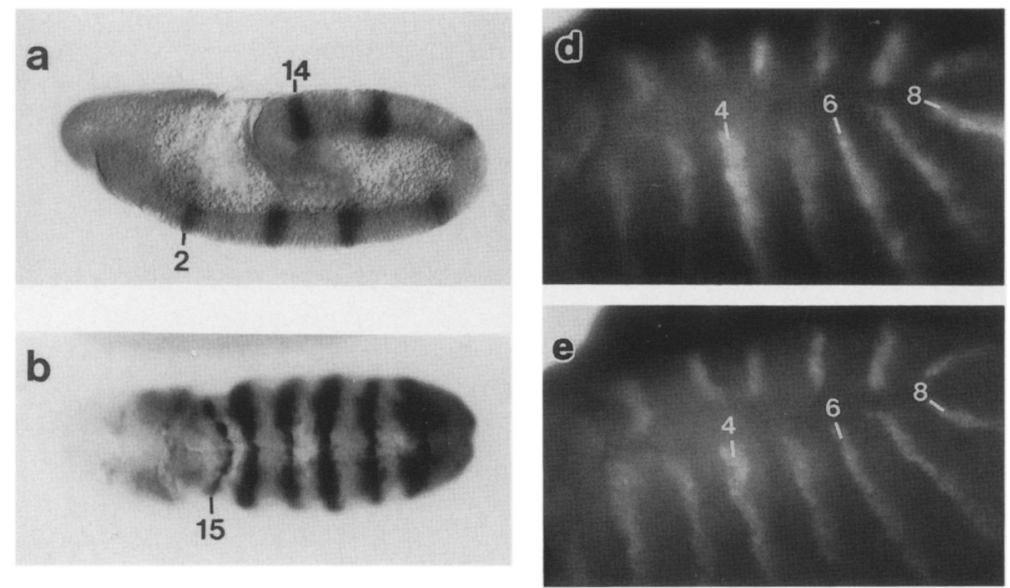

Figure 2. Striped expression from intron-containing constructs at different developmental stages. $(a-c)$ B-transformant embryos stained with rabbit anti- $\beta$-galactosidase antibody visualized by immunoperoxidase staining. All embryos are oriented with anterior left, dorsal up. (a) 3.5-4 hr AEL. The even-numbered stripes are much darker than the odd-numbered stripes at this stage. $(b)$ dorsal view, $\sim 6 \mathrm{hr}$ AEL. $(c) \sim 9 \mathrm{hr}$ AEL. Location of $\beta$-galactosidase stripes is just anterior to the segment border, in the same place as en. $(d$ and $e / \mathrm{E}$ transformant doubly labeled with immunofluorescent antibodies to reveal expression of $\beta$-galactosidase $(d)$ and endogenous en $|e|, \sim 5 \mathrm{hr}$ AEL. En antigen $(e)$ is nuclear and therefore more discrete then the cytoplasmically located $\beta$-galactosidase antigen. served sequences (Kassis et al. 1986). Surprisingly, when the D. melanogaster intron 1 is added to A (B in Fig. 1a), $\beta$-galactosidase is expressed in the ectoderm in en-like stripes (Fig. 2). $\beta$-Galactosidase protein stripes are first detected at $\sim 3.5 \mathrm{hr}$ after egg laying (AEL) and are maintained throughout embryonic development (Fig. 2a-c; also see Fig. 8 b, below). Double-labeling of transformant embryos with anti- $\beta$-galactosidase and anti-en antibodies shows that the $\beta$-galactosidase stripes are coincident with en stripes in a germ-band elongated embryo (Fig. 2d, e).

Intron 1 contains $\sim 300$ bp of DNA highly conserved between $D$. melanogaster and $D$. virilis (Kassis et al. 1986). To test whether the conserved sequences may be responsible for stripe formation, I compared the activities of $D$. melanogaster and $D$. virilis intron fragments. The $D$. melanogaster intron fragment extends from 26 bp before the splice site to intron base 1042, 91 bases before the $3^{\prime}$ end of the intron. The homologous $D$. virilis fragment extends from intron base 355 through 1618, 119 bases before the $3^{\prime}$ end of the intron. These two fragments contain most of the DNA conserved between the two introns (Kassis et al. 1986). Striped expression from the $D$. virilis intron-containing constructs is indistinguishable from that of the $D$. melanogaster intron-containing construct in a wild-type background, suggesting that the conserved sequences may be responsible for striped expression.

\section{Intron 1 works as a stripe-specific enhancer}

The $D$. virilis intron can generate striped expression when cloned upstream (in either orientation) of en sequences or downstream of the transcription unit $(B, C$, $D$, and E in Fig. 1a; data not shown). This suggests that the intron acts as a stripe-specific enhancer. To test its ability to induce striped expression alone, I cloned the $D$. virilis intron upstream of a heterologous promoter, $h s p 70$, driving the expression of $\beta$-galactosidase /construct $\mathrm{J})$. Eleven lines were examined for $\beta$-galactosidase activity, and no stripes were made at any stage (see Fig. 8 , below). However, high levels of $\beta$-galactosidase activity were evident in the progenitor of the fat body and in some specific neurons, indicating that the intron could induce $\beta$-galactosidase expression from the heat shock promoter in some tissues (see below). This led me to conclude that a combination of upstream en and intron sequences were required to induce stripes.

To test this hypothesis, deletions of en upstream sequences were combined with the $D$. virilis intron. en expression is thought to be regulated, in part, by homeo domain-containing proteins (Howard and Ingham 1986; DiNardo and O'Farrell 1987). There is a cluster of homeo domain-binding sites located between -854 and -950 bp upstream of the transcription start site (Desplan et al. 1988; Kassis et al. 1989). I tested the effect of deletion of those binding sites on expression (G in Fig. la). Deletion of the upstream homeo domain-binding site cluster did not alter the expression pattern, indicating that those sites are not important for striped expression from this construct (data not shown).

I tested the ability of the $D$. virilis intron to induce stripes with a much smaller fragment of en upstream sequences, one that extends to only -400 (I in Fig. 1a). Striped expression from this construct was indistinguishable from that with upstream sequences extending to $-2.4 \mathrm{~kb}$ /although expression levels may be somewhat reduced; data not shown). This led me to suspect that most of the sequences required for striped expression were present within the intron and to test its activity with another heterologous promoter, the white promoter. 

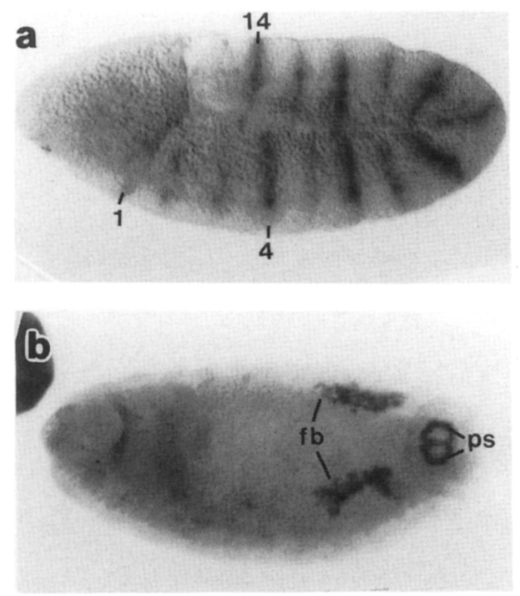

Figure 3. The intron alone induces striped expression of the white gene. white RNA is shown in J embryos at two developmental stages. $(a) \sim 5.5 \mathrm{hr}$ AEL $(b) \sim 12 \mathrm{hr}$ AEL. (fb) Progenitor of the fat body; (ps) posterior spiracles. white RNA is also expressed in several specific neurons at this stage, but these are not evident in this embryo.

\section{The white gene can be used as a reporter gene}

Located within all my of P-element constructs is the white gene, included as a selectable marker for transformants (see Fig. lb). Here I also use it as a reporter gene by asking whether the en intron can induce white expression in the embryo. Surprisingly, white RNA is present in stripes in J embryos (Fig. 3a). Thus, whereas the $D$. virilis intron alone cannot efficiently induce striped expression of $\beta$-galactosidase from the $h s p 70$ promoter, it is sufficient to induce striped expression from the white promoter. Later in development, white RNA in J embryos is seen in the same tissues as $\beta$-galactosidase (Fig. 3b, see below).

\section{The intron lacks sequences necessary for striped expression late in embryogenesis}

en is expressed in stripes throughout almost all of embryogenesis. en RNA and protein have short half-lives (DiNardo et al. 1988; Weir et al. 1988). In contrast, Escherichia coli $\beta$-galactosidase is a long-lived protein in Drosophila (Hiromi et al. 1985; see below). Therefore, although it is a good marker for determining when a gene is turned on, it does not indicate when it stops being transcribed. For en, which is subject to regulation throughout development, this presents a problem. I have taken advantage of the fact that a fusion protein consisting of 296 amino acids of en protein fused to the $\beta$ galactosidase protein (en/ $\beta$-gal) has a turnover rate similar to en (DiNardo et al. 1988). When a construct is made with the short-lived $e n / \beta$-gal fusion protein $\langle\mathrm{F}$ in Fig. 1), $\beta$-galactosidase expression is similar to that of the construct with the more stable reporter protein through $6 \mathrm{hr}$ of development (Fig. $4 \mathrm{a}, \mathrm{b}$ ). However, as the germ band begins to shorten, the en/ $\beta$-gal protein fades, and by $8 \mathrm{hr}$ of development no stripes are visible (Fig.
$4 c, d)$. The simplest interpretation of this result is that these constructs lack those sequences necessary to transcribe $\beta$-galactosidase in stripes late in development.

Similar results were obtained when examining the RNA produced from constructs encoding the more stable protein (Fig. $5 \mathrm{e}-\mathrm{h}$ ). (The D. melanogaster and $D$. virilis introns gave similar results). $\beta$-Galactosidase-containing RNA was detected slightly earlier than protein, at the start of gastrulation (data not shown). $\beta$-Galactosidase RNA stripes resemble $\beta$-galactosidase protein stripes until the onset of germ-band shortening when the RNA stripes rapidly fade (Fig. $5 \mathrm{~h}$ ) and are totally absent in a shortened embryo. In contrast, the $\beta$-galactosidase protein remains in stripes late in embryogenesis (see Fig. 8b, below). This result shows that it is the $\beta$-galactosidase protein that is stable in the embryos and not the RNA produced from these constructs.

\section{The intron containing lac $\mathrm{Z}$ constructs respond to the same spatial cues as en}

During development, the embryo can be divided into 15 parasegments, with one en stripe per parasegment (numbered 1-15; These correspond approximately to the 3 oral, 3 thoracic, and 9 abdominal segments; MartinezArias and Lawrence 1985.) en expression in stripes is thought to be regulated (at least in part) by the activity of other segmentation genes. This is because en stripes are altered in segmentation mutants. Pair-rule genes are thought to initiate en expression in stripes (Howard and Ingham 1986; DiNardo and O'Farrell 1987). Mutations in a particular pair-rule gene affect the formation of $e n$ stripes in either the even- or the odd-numbered parasegments. For example, in the pair-rule mutant fushi tarazu (ftz), only the odd-numbered stripes are formed. In contrast, mutations in segment polarity genes affect every stripe, and these effects are seen later in development. I examined the $\beta$-galactosidase expression pattern of $\mathrm{E}$ embryos in a number of different segmentation mutant backgrounds to assess how accurately it mimics that of $e n$. This analysis should give some indication of the regulatory signals to which the intron can respond.

$\beta$-Galactosidase expression from E closely mimics en expression in a number of different mutants: $\beta$-galactosidase stripes in the pair-rule mutants $f t z$, paired (prd), and odd-skipped and in the segment polarity mutant naked (nkd) closely resemble en stripes (Fig. 5). Because the $\beta$-galactosidase stripes lag behind the appearance of en stripes, it was important to access whether they were simply being activated by $e n$. The presence of $15 \mathrm{\beta}$-galactosidase stripes in an embryo that totally lacks the en gene shows that this is not the case (Fig. $5 \mathrm{~g}, \mathrm{~h})$. (Constructs $B$ and $\mathrm{E}$ gave similar results in an en mutant.)

wingless is required for the activation of the odd-numbered stripes from the intron

wingless $(\mathrm{wg})$ is a segment polarity gene which seems to be an activator of en expression. In a wg mutant, all 15 en stripes form normally but then fade late in germ-band 

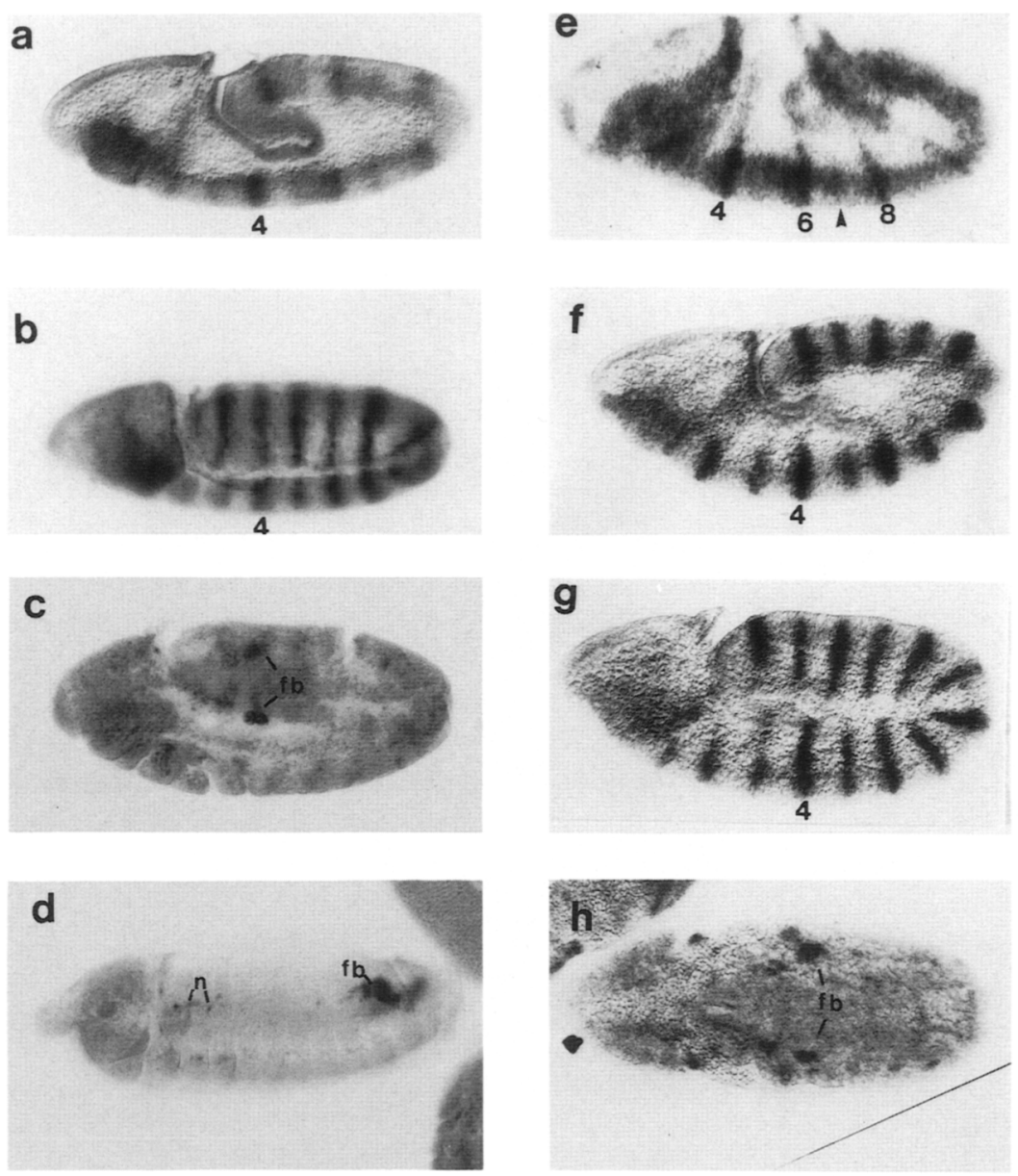

Figure 4. Striped expression from the introncontaining constructs disappears in shortening embryos. All embryos are oriented with anterior left, dorsal up. $(a-d) \beta$-Galactosidase protein visualized by immunoperoxidase staining in F embryos. $(a) \sim 3.5-4 \mathrm{hr}$ AEL. $(b) \sim 5 \mathrm{hr}$ AEL. Notice that stripes 1-3 are lighter. This is a characteristic of all intron-containing lines at this stage in development and is not true for en stripes. (c) Dorsal view, $\sim 7.5 \mathrm{hr}$ AEL. Stripes are only weakly present. Expression in the progenitor of the fat body $(\mathrm{fb})$ is evident. $(d) \sim 10 \mathrm{hr}$ AEL. $\beta$-Galactosidase is detected in the progenitor of the fat body and in some developing neurons $(\mathrm{n}) \cdot(e-h) \beta$-Galactosidase RNA in $\mathbf{E}$ embryos. $(e) \sim 3.5 \mathrm{hr}$ AEL. Even-numbered stripes are evident; odd-numbered stripes are barely visible (arrowhead). $(f) \sim 4.5 \mathrm{hr}$ AEL. $(g)$ $\sim 5 \mathrm{hr}$ AEL. Stripes $1-3$ are lighter. $(h) \sim 7.5 \mathrm{hr}$ AEL. Dorsal view, shortening embryo. Stripes are mostly gone. $\beta$-Galactosidase in the progenitor of the fat body $(\mathrm{fb})$ is evident. (B, C, D, E, F, G, and I gave similar results as did the expression of the white gene from J.) extension (DiNardo et al. 1988; Martinez-Arias et al. 1988). Thus, wg activity is important for maintaining en stripes late in development.

In $w g$ mutants, $\beta$-galactosidase stripes expressed from intron-containing constructs differ from en stripes. Whereas all 15 en stripes are formed in wg mutants (DiNardo et al 1988; Martinez-Arias et al. 1988), only the 7 even-numbered $\beta$-galactosidase stripes are fully formed from B and E (Fig. 6, E is shown); the odd-numbered stripes are largely absent. This suggests that the odd-numbered $\beta$-galactosidase stripes are largely activated by $w g$ activity. In contrast, the presence of the even-numbered $\beta$-galactosidase stripes in $w g$ mutants suggests that they are turned on first by pair-rule genes. In a wild-type background, the even-numbered $\beta$-galactosidase stripes are darker than the odd-numbered stripes, reflecting their activation by both the pair-rule genes and $w g$ activity.

A species-specific difference in a patched background suggests that multiple regulatory programs inhibit en expression between stripes

patched (ptc) is a segment polarity gene that acts to suppress en expression between stripes. In a ptc mutant, en expression is normal until $\sim 4.5 \mathrm{hr}$ of development, when an extra "stripe" begins to form between each of the normal stripes (DiNardo et al. 1988; Martinez-Arias et al. 1988). $\beta$-Galactosidase expression from B is quite similar to en expression in a ptc mutant (Fig. 7a,b). In contrast, $\beta$-galactosidase expression from $\mathrm{E}$ (which contains the $D$. virilis intron) is more generally derepressed than en. First, defects in $\beta$-galactosidase stripes from $\mathrm{E}$ occur earlier in development than defects in en stripes. Figure $7 \mathrm{c}$ shows a ptc mutant embryo at $\sim 4 \mathrm{hr}$ of development, where $\beta$-galactosidase stripes numbered 12 and 14 are much wider than normal stripes. Later in development, this defect is present in every stripe and is quite pronounced (Fig. 7d). These results suggest that the $D$. virilis intron responds poorly to a repression system active at endogenous en, which keeps en defects narrowly confined in a ptc mutant.

The intron also induces expression in the progenitor of the fat body and some specific neurons

The intron sequences contain an additional tissue-specific enhancer function. As discussed above, the intron in the presence of the heat shock promoter fails to produce $\beta$-galactosidase protein stripes (construct J). However, $\beta$-galactosidase protein is evident after $10 \mathrm{hr}$ of development in groups of cells in the anterior and posterior 
Figure 5. $\beta$-Galactosidase expression from $E$ in various segmentation mutants. (a) ftz mutant, $\sim 7.5$ hr AEL. (Looking down on a germ-band-shortening embryo). Anti- $\beta$-galactosidase antibody, immunoperoxidase staining. $\beta$-Galactosidase expression is similar to en expression in $f t z$ mutants; only the seven odd-numbered stripes are present. (b) prd mu$\tan t-\beta$-galactosidase expression is similar to en expression in a prd mutant; only the even-numbered stripes are present. $(c-d) \beta$-Galactosidase $(c)$ and en $(d)$ in an odd-skipped mutant. View is looking down on the posterior region of a fully germ-band-extended embryo $\sim 6 \mathrm{hr}$ AEL. ( $e$ and $f) \beta$-Galactosidase $(e)$ and $e n(f)$ in a nkd mutant. $\sim 6 \mathrm{hr}$ AEL. $(g$ and $h)$ $\beta$-Galactosidase $(g)$ and $e n(h)$ expression in an embryo that lacks the en gene. All $15 \beta$-galactosidase stripes are made in the absence of en. An embryo containing one copy of $e n$ is visible at the lower left. (B gave a similar result in en mutants.)
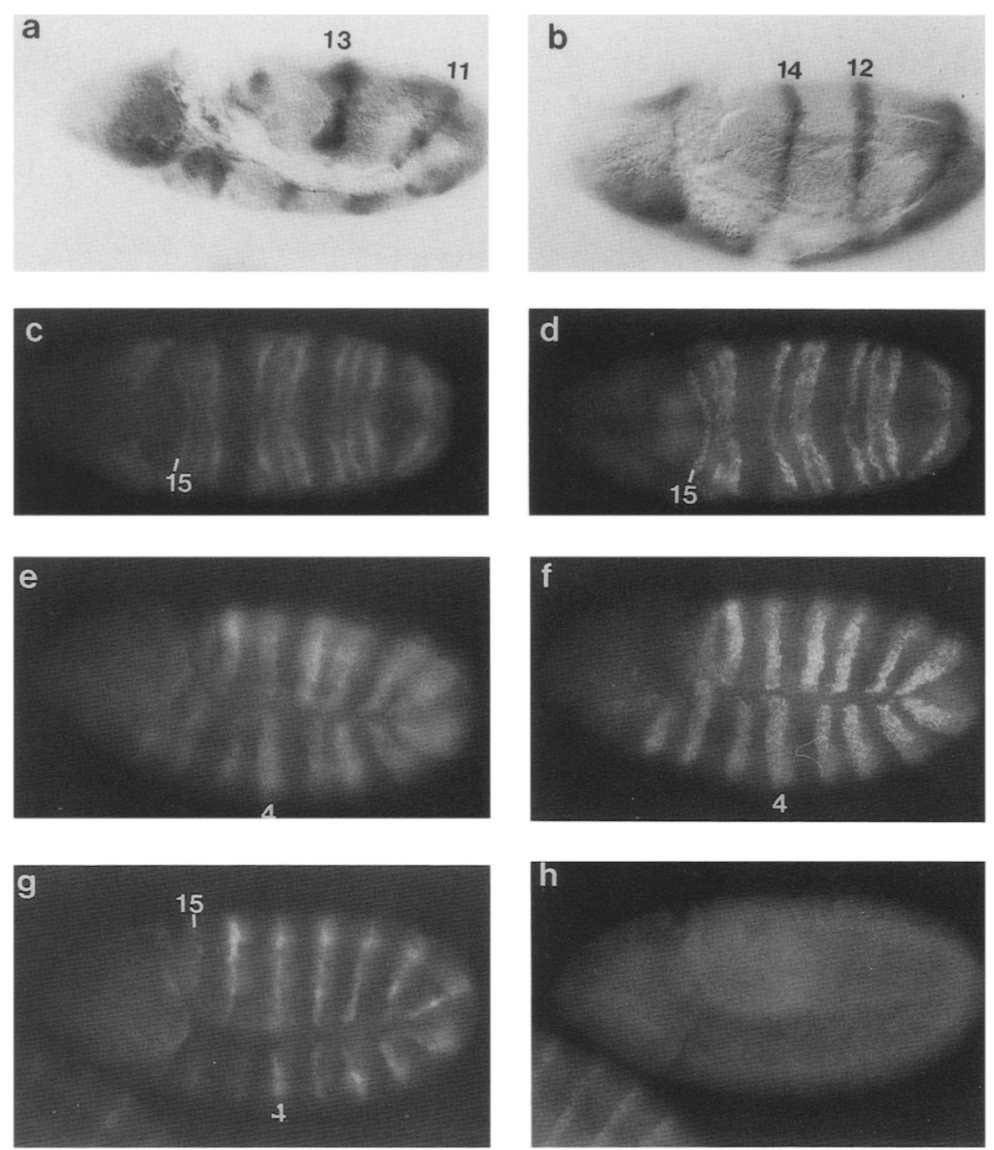

regions of the embryo (Fig. 8 d; see also Fig. 4 d). Figure $8 \mathrm{a}$ shows a J embryo at $\sim 13-15 \mathrm{hr}$ AEL when $\beta$-galactosidase is detected in the progenitor of the fat body, posterior spiracles, and several neurons. The $D$. virilis intron
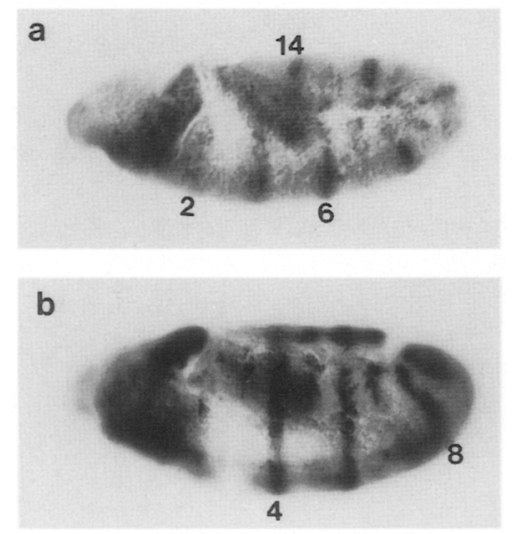

Figure 6. Only the even-numbered $\beta$-galactosidase stripes are fully formed in a wg mutant. $\beta$-Galactosidase expressed from $E$ in a wg mutant. $(a) \sim 4.5 \mathrm{hr}$ AEL. Even stripes are present; odd stripes are very weak and largely confined to the dorsal region. (b) $\sim 6 \mathrm{hr}$ AEL. Odd-numbered stripes still have not fully formed. There is some dorsal expression seen in the odd-numbered parasegments. These may be the same as the weak dorsal stripes produced in P-element lines in the absence of an enhancer (see Results). Similar results were obtained when construct B was in a wg mutant. also induces $\beta$-galactosidase expression in these tissues when in combination with the en promoter (in C, D, E, $\mathrm{F}, \mathrm{G}$, and I embryos; $\mathrm{E}$ is shown in Fig. $8 \mathrm{~b}$ ). The $D$. melanogaster intron also induces $\beta$-galactosidase expression in the progenitor of the fat body and the same neurons but not in the spiracles (data not shown). This suggests that in addition to its ability to cause expression in stripes, expression in the fat body and a few specific neurons is also a conserved feature of en intron 1. Although en has not been reported to be expressed in these neurons or in the developing fat body, careful examination of germ-band-shortened embryos indicates that en is indeed transiently expressed in the developing fat body (Fig. 8c). A J embryo at a similar stage is shown in Figure $8 \mathrm{~d}$ for comparison. en protein can no longer be detected at $12 \mathrm{hr}$ AEL when $\beta$-galactosidase RNA is still easily detectable in the transformants (data not shown; see white RNA in Fig. $3 \mathrm{~b}$ ). This seems to indicate that sequences required to turn off $\beta$-galactosidase expression in this tissue later in development are not present within the intron. Alternatively, $\beta$-galactosidase and white RNA could be more stable than the en protein in this tissue.

\section{Discussion}

There are three principle conclusions of the work presented here. First, intron 1 of the en gene contains conserved regulatory sequences that lead to striped expres- 

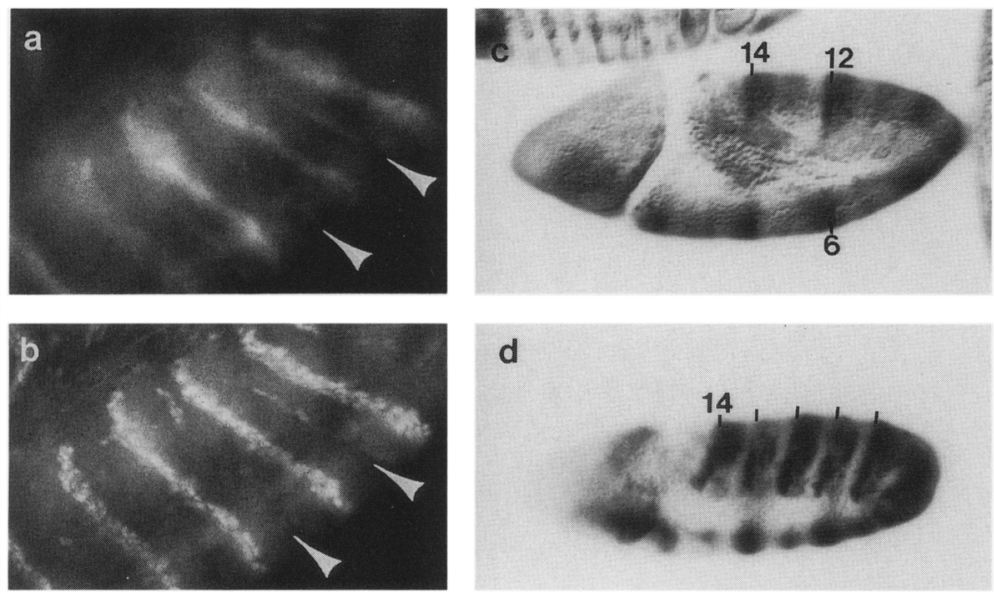

Figure 7. The $D$. virilis and $D$. melanogaster intron-containing constructs behave differently in $p t c$ mutants. $(a$ and $b) \mathrm{B}$ in a ptc mutant. Doubly labeled embryo stained for $\beta$-galactosidase $(a)$ and en $(b)$. Enlarged view of embryo $\sim 6 \mathrm{hr}$ AEL. Expression of $\beta$-galactosidase is confined to normal stripes and regions next to new furrows (arrowheads) similar to en. $(c$ and $d) \beta$-Galactosidase produced from the $D$. virilis intron in ptc mutants (c) F embryo, $\sim 3.5-4 \mathrm{hr}$ AEL. Some stripes are too wide. This is especially evident in stripes 12 and 14. (d) E embryo, $\sim 6 \mathrm{hr}$ AEL. Very wide stripes are quite evident at this stage. Normal location of the stripes is indicated by the lines. In some segments the normal part of the stripe is the darkest part. sion. Second, different regulatory sequences are required for en stripes at different times in development. This emphasizes the dynamic nature of en stripes, and suggests continual control of stripes throughout development. Third, control elements that produce apparently normal stripes in a wild-type background may lack the ability to respond to aspects of regulation uncovered in mutant backgrounds. The general derepression of $\beta$-galactosidase stripes produced by the $D$. virilis intron in a ptc mutant suggests that multiple repression programs keep en expression off between stripes.

\section{en intron 1 is sufficient for striped expression}

en intron 1 contains conserved regulatory DNA that leads to expression in stripes and in two other tissues: the progenitor of the fat body and some specific neurons. The ability of the $D$. virilis intron to induce stripes is dependent on the type of promoter with which it is combined. Although strong stripes are generated when combined with the en or the white promoter, striped ex- pression from the hsp70 promoter is extremely weak. This indicates that the $h s p 70$ promoter does not work well with the stripe enhancer. In contrast, expression in the fat body and neurons is equally strong with all promoters. This suggests that the proteins controlling expression in stripes are different from those controlling expression in the other tissues. The en promoter differs from the $h s p 70$ promoter in that it has no TATA box and requires sequences within the transcribed region for activity (Soeller et al. 1988). Although little is known about the white promoter, it does not appear to have a TATA box. No obvious sequence similarities were found between white and en promoters, however, it is possible that they interact with similar factors.

\section{At least three temporally overlapping regulatory programs activate en expression in stripes}

Expression of en in various segmentation mutants indicated that en stripes are controlled by at least two regu-
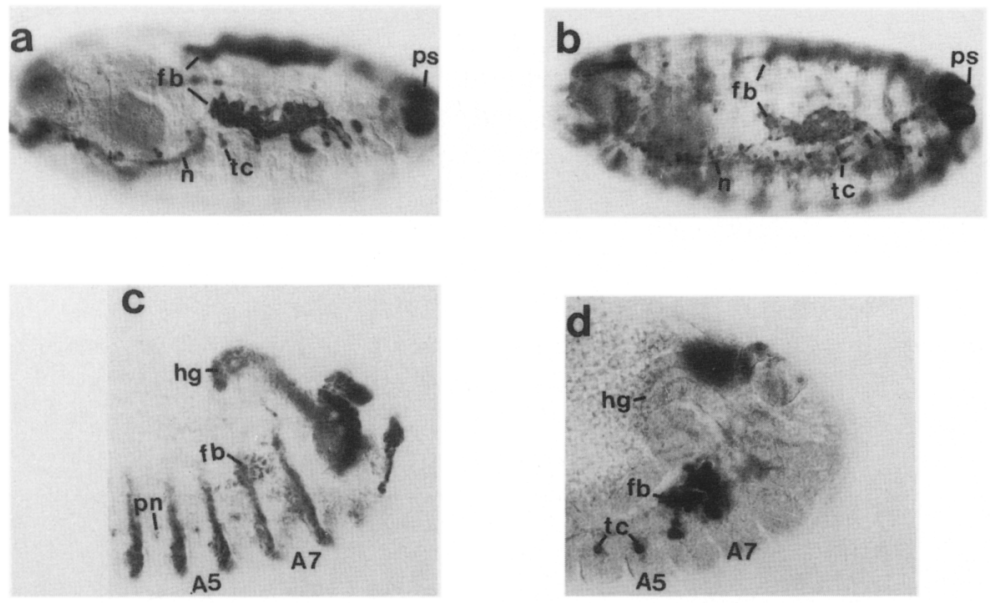

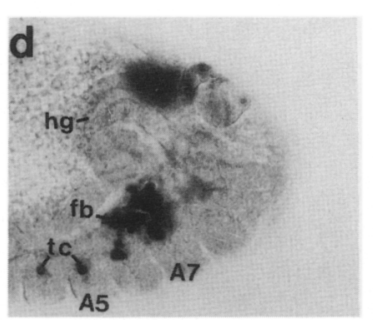

Figure 8. Intron sequences induce $\beta$-galactosidase expression in a portion of the developing fat body and specific neurons. Embryos are stained with anti$\beta$-galactosidase antibody or anti-en antibody $(c)$ visualized by immunoperoxidase staining. (Orientation, anterior left, dorsal up.) (a) J embryo 13-15 hr AEL. Focus is just below the ectoderm on the dorsal surface. (ps) Posterior spiracles; (fb) a portion of the developing fat body; (n) neuron. Tracheal cell (tc) expression was also seen in some lines that did not contain the intron and, therefore, may not be due to sequences within the intron. (b) E transformant at a similar stage and focal plane. Notice the stripes in this embryo not present in $a$. $(c)$ en antigen visualized by immunoperoxidase staining to show expression in cells of the developing fat body. Germ-bandshortened embryo $\sim 10 \mathrm{hr}$ AEL, only area of interest is shown (magnified). Focal plane is just below the

surface. (hg) Hindgut; (A5, A7) abdominal segments 5 and 7 ; (pn) peripheral neuron. A portion of the hindgut and some peripheral neurons also expresses en protein, and these are evident here. (d) J embryo at approximately the same stage and view as embryo in $c$ stained to visualize $\beta$-galactosidase antigen. $\beta$-Galactosidase fills the large cells, whereas en is confined to the nucleus. The tracheal cells (tc) are also apparent in this embryo. 


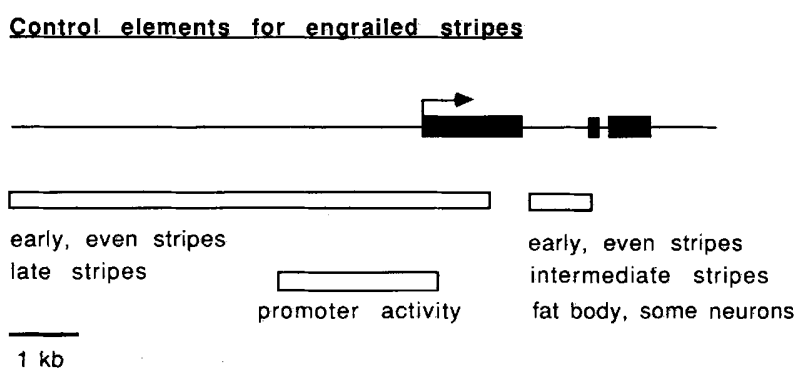

Figure 9. Control elements for en stripes. The thin line represents en DNA. Dark boxes indicate en exons. The arrow indicates the start site of en transcription. The open boxes indicate cis-acting regulatory sequences located to date; written below are the programs to which they apparently respond. The upstream regulatory element is $\mathrm{P}[\mathrm{en} / \mathrm{lac}]$ from DiNardo et al. (1988). It includes en sequences from -10.7 to -7.1 and -4.2 to $+1099 \mathrm{~kb}$. The fragment indicated as promoter activity only extends from -2.4 to $+188 \mathrm{~kb}$ ( $\mathrm{A}$ in Fig. 1 ; this study). The intron can be from either $D$. virilis or $D$. melanogaster /this study|.

latory circuits: one involving the pair-rule genes that initiate striped expression and a second for maintenance of striped expression, dependent on the activity of the segment polarity genes (DiNardo et al. 1988; MartinezArias et al. 1988). Studies on the cis-acting regulatory sequences of en indicate further complexities. Comparison of $\beta$-galactosidase expression patterns generated by the intron and by a previously reported construct that contains only upstream en sequences (from DiNardo et al. 1988; see Fig. 9) indicates the presence of at least three regulatory programs for activating en expression in stripes: an early program activated by the pair-rule genes; an intermediate program activated by the segment polarity gene $w g$; and a late program, necessary for striped expression subsequent to the onset of germ-band shortening.

The early program activates en stripes from 3 to $5 \mathrm{hr}$ of development Both upstream en sequences alone and the intron alone are able to induce $\beta$-galactosidase in even-numbered stripes early in development (from DiNardo et al. 1988 and this paper). This indicates that the information for the early, even-numbered stripes is present at least twice within en regulatory DNA. Genetic arguments suggest that these early stripes are activated by the pair-rule genes (Howard and Ingham 1986; DiNardo and O'Farrell 1987). The end of the early program is suggested by the fading of the even-numbered stripes driven by the upstream sequences at $\sim 5 \mathrm{hr}$ of development (DiNardo et al. 1988). This is a little later than the stripes of the pair-rule gene product, $f t z$ protein, disappear (Carroll and Scott 1984).

The intermediate program activates en stripes from 4 to $7 \mathrm{hr}$ of development Differences in the time of appearance of the odd stripes driven by the upstream or intron sequences and the behavior of the odd stripes in en mutants suggest the presence of an intermediate program. Odd-numbered stripes from the intron construct are evident at $\sim 4 \mathrm{hr}$ of development (soon after the appearance of $w g)$. Odd-numbered stripes from the upstream construct are not evident until $\sim 5 \mathrm{hr}$ of development. Furthermore, in en mutants, the odd stripes generated by the intron are present, whereas those generated from the upstream construct are not (J. Heemskerk, S. DiNardo, and P.H. O'Farrell, pers. comm.). The intermediate program is apparently activated by $w g$, as no odd stripes form from the intron constructs in a wg mutant. The end of this program is indicated by the loss of stripes from the intron constructs upon germ-band shortening. Thus, wg seems to be required to activate en expression only transiently. (A similar proposal was suggested by Nakano et al. 1989.)

The late program activates en stripes beginning at $\sim 5 \mathrm{hr}$ of development In transformants with the upstream DNA, $\beta$-galactosidase stripes are expressed subsequent to germ-band shortening. Expression of stripes in every segment begins at $\sim 5 \mathrm{hr}$ of development (only the evennumbered stripes are present earlier). An active en gene is necessary for the formation of the late stripes from the upstream sequences (J. Heemskerk, P.H. O'Farrell and S. DiNardo, pers. comm.). Thus, en is required for stripe formation late in development. The $\beta$-galactosidase stripes produced from the upstream construct are not as complete ventrally and do not persist as late in development as en stripes (DiNardo et al. 1988). Thus, it is clear that not all of the control elements of en stripes have been located.

\section{Multiple programs of repression keep en confined to stripes}

$p t c$ is a segment polarity gene expressed in wide stripes early in development (Hooper and Scott 1989; Nakano et al. 1989). Initially, the ptc stripes include all cells except those that express en (Hooper and Scott 1989; Nakano et al. 1989). This suggests that early in development, the presence of ptc may repress en expression. Further complications arise later in development.

In a ptc mutant, defects in striped expression from the $D$. virilis intron occur early in development. This suggests that in wild-type embryos, ptc activity acts early in development (when the ptc product is first produced) to keep expression from the $D$. virilis intron confined to stripes. The fact that en stripes are not too wide early in development in a ptc mutant suggests that there may be another repression system whose activity overlaps with that of ptc early in development. The inability of the $D$. virilis intron to respond to this other repression system does not necessarily indicate a lack of such a system in $D$. virilis. Instead, some of the cis-acting sequences required to respond to this system may be located elsewhere in the $D$. virilis en gene.

\section{Prospects for understanding regulation of en stripes on a molecular level}

The intron seems to contain sequences that respond to those pair-rule genes controlling expression in the evennumbered stripes (see Results). One such gene is $f t z$. In 
the absence of $f t z$ activity, the even-numbered en stripes do not form (Howard and Ingham 1986; DiNardo and $\mathrm{O}^{\prime}$ Farrell 1987). This suggests that $f t z$ activates en expression in the even-numbered stripes, but does not indicate whether this action is direct or indirect. The $f t z$ protein contains a homeo domain (Laughon and Scott 1984), can bind DNA in vitro (Desplan et al. 1988), and can activate transcription in tissue culture cells through homeo domain-binding sites (Jaynes and O'Farrell 1988; Han et al. 1989). Interestingly, one of the homeo domain-binding site clusters through which $f t z$ can act in cell culture is located within the upstream en sequences tested here (Han et al. 1989). From my constructs, I have shown that these sequences are not important for striped expression. This suggests that although $f t z$ can act through these sites in cell culture, it may not act through them in vivo. However, located within the first intron is another cluster of conserved homeo domainbinding sites to which $\mathrm{ftz}$ can also bind in vitro (Kassis et al. 1989; C. Desplan, pers. comm.). We are currently investigating whether alteration of the intron homeo domain-binding sites alters striped expression. These experiments should indicate whether $f t z$ activates en expression directly.

The intron contains sequences that respond to the segment polarity genes ptc and wg This is particularly exciting because neither $p t c$ nor $w g$ encodes a nuclear protein. $w g$ is homologous to the mammalian oncogene intl, which is thought to be a secreted protein (Cabrera et al. 1987; Rijsewijk et al. 1987). ptc seems to encode a membrane protein (Hooper and Scott 1989; Nakano et al. 1989). Both of these proteins are thought to be involved in cell-cell communication (for review, see Ingham 1988). Thus, their effects on en expression are unlikely to be direct. Instead, a signal must be generated that results in the control of en expression. The DNAbinding proteins through which those signals act are likely to bind to sequences within the en intron.

\section{Methods}

\section{Plasmid constructions and germ line transformations}

All of the constructs shown in Figure la were cloned into the EcoRI site of the transformation vector CaSpeR (Pirotta 1988), which contains the white gene as a marker. The orientation of all inserts within the vector is as depicted in Figure 1b. Construct A was also cloned into Carnegie 20.1, which contains the rosy gene as a marker; three of the lines discussed were in this vector. $\mathrm{H}$ was also in the Carnegie 20 vector. The $3^{\prime}$ end of the en upstream sequences was generated by ExoIII deletion (Henikoff 1984) resulting in the absence of 25 bases of the en-untranslated leader. The $D$. virilis intron 1 fragment includes intron bases 355-1618 (BglII-SphI) (numbering is from the first base in the intron; Kassis et al. 1986). The D. melanogaster intron 1 fragment begins 17 bases before the splice site and extends through 1042 (PvuI-EcoRI). For G, a 96-bp StuI-ClaI fragment (which extends from -854 to -950 , Kassis et al. 1989) that contains five homeo domain-binding sites was deleted from the upstream fragment (kindly provided by C. Desplan). The upstream en DNA in $\mathrm{H}$ extends from an SphI site at -400 to +188 . (Detailed cloning procedures are available on request.)
Transgenic flies were made by standard methods (Rubin and Spradling 1982). Injections were into $D f(1) w 67 c 2, y$. Some of the independent lines used in this study were generated by mobilization of P-element constructs in a strain that supplies the $P$ transposase (Robertson et al. 1988). The number of lines for each was: $6 \mathrm{~A} ; 4 \mathrm{~B} ; 2 \mathrm{C} ; 1 \mathrm{D} ; 6 \mathrm{E} ; 2 \mathrm{~F} ; 5 \mathrm{G} ; 2 \mathrm{H} ; 2 \mathrm{I} ; 11 \mathrm{~J}$ (only 2 were examined for white RNA expression in embryos). Ten control lines containing the hsp 70 promoter without the intron (not shown) were examined; none had an expression pattern similar to that seen in J. One heat shock response element was present in the $h s p 70$ fragment used, and $\beta$-galactosidase expression was weakly inducible by heat shock. Also, four lines of a construction that contains the same upstream sequences as $\mathrm{A}$ were examined, except the $e n / \beta$-gal fusion protein was made. (These lines were made by Elizabeth Sher.) Like A, this construct contains only promoter activity.

\section{Analysis of $\beta$-galactosidase expression patterns}

Embryos from each transformant line were examined first for $\beta$-galactosidase activity using an X-gal assay (Hiromi et al.). One or two lines from each construction were examined further by staining with anti- $\beta$-galactosidase antibodies. Note that no $\beta$-galactosidase activity could be detected in F embryos, whereas the antigen was easily detectable. The expression patterns described here are those common to all transformant lines examined. Many of the lines had additional expression patterns late in development dependent on the position of the insert within the genome. These are not discussed. In addition, the level of $\beta$-galactosidase produced was very dependent on the location of the insert in the genome. In lines generated by movement of the P-element insert, occasionally no $\beta$-galactosidase activity was observed. Although this was probably due to a change in DNA on movement, it was not examined, and these lines were ignored.

Preparation of embryos for immunocytochemistry was as in DiNardo and O'Farrell (1987). Rabbit anti- $\beta$-galactosidase was from Cappel (used at a dilution of $1: 3000$ ), mouse monoclonal antibody against en (and inv) (used at a dilution of $1: 2$ ) was a gift of D.H. Huang (originally from the laboratories of T. Kornberg and C. Goodman; Patel et al. 1989).

Detection of RNA was by the nonradioactive method of Tautz and Pfeifle (1989). For detection of $\beta$-galactosidase RNA a pC4ATG- $\beta$-gal (Thummel et al. 1988) plasmid, which included a piece of the $h s p 70$ promoter (from -73 to +70 ), was labeled by random priming using the Genius kit (Boehringer-Mannheim). For detection of white RNA, a SacI fragment extending from the polylinker in the CaSpeR vector to the Sacl site within the white gene was labeled. Embryos were mounted in Fluoromount G (FisherBiotech) and examined using Nomarski optics.

\section{Examination of expression patterns in mutants}

Transformants containing an insert on a chromosome different from the one containing the mutation of interest were crossed to the mutant stock. In the next generation, flies that contained one copy of the insert and that were heterozygous for the mutation were crossed to each other. Mutant embryos were detected by identifying known disruptions in en patterns in double-labeling experiments (anti-en and anti- $\beta$-galactosidase) and by altered expression patterns in embryos treated with anti- $\beta$-galactosidase antibodies followed by immunoperoxidase staining. Mutant combinations used were en: $D f(2 R)$ en28/Df(2R)enX31, which contains no en or inv DNA; odd-skipped, oddIIID86/

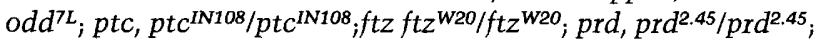
$w g, w^{C X 4} / w^{C X 4} ; n k d, n k d^{7 E 89} / n k d^{Y E 88}$. 


\section{Acknowledgments}

I am indebted to Mary Jane Walling and Page VanSickle for excellent technical assistance; S. DiNardo for advice and enthusiasm, J. Heemskerk for examining expression patterns from many early constructs, D. Smouse (and numerous others) for help in identifying the $\beta$-galactosidase-expressing structures in the late embryos, C. Thummel and A. Boulet for vectors and flies, G. del Puerto and J. Kennison for mutant stocks, J. Hooper and $\mathrm{M}$. Scott for communicating ptc results prior to publication. J. Heemskerk, J. Kennison, P. Noguchi, and W. Odenwald deserve thanks for comments on numerous versions of this manuscript. I also thank the referees of this manuscript for helpful comments. Experiments were initiated while J.A.K. was a postdoctoral fellow (supported by the Giannini Foundation) in the laboratory of P.H. O'Farrell.

\section{References}

Bellen, H.J., C.J. O'Kane, C. Wilson, U. Grossniklaus, R.K. Pearson, and W.J. Gehring. 1989. P-element-mediated enhancer detection: A versatile method to study development in Drosophila. Genes Dev. 3: 1288-1300.

Bier, E., H. Vaessin, S. Shepherd, D. Lee, S.K. McCall, S. Barbel, L. Ackerman, R. Carretto, T. Uemura, E. Grell, L.Y. Jan, and Y.N. Jan. 1989. Searching for pattern and mutation in the Drosophila genome with a P-lacZ vector. Genes Dev. 3: $1273-1287$.

Cabrera, C.V., M.C. Alonso, P. Johnston, R.G. Phillips, and P.A. Lawrence. 1987. Phenocopies induced with antisense RNA identify the wg gene. Cell 50: 659-663.

Carroll, S.B. and M.P. Scott. 1984. Zygotically active genes that affect the spatial expression of the fushi tarazu segmentation gene during early Drosophila embryogenesis. Cell 45: $113-126$.

Desplan, C., J. Theis, and P.H. O'Farrell. 1988. The sequence specificity of homeo-domain-DNA interaction. Cell 54: $1081-1090$.

DiNardo, S. and P.H. O'Farrell. 1987. Establishment and refinement of segmental pattern in the Drosophila embryo: spatial control of en expression by pair-rule genes. Genes Dev. 1: $1212-1225$.

DiNardo, S., J.M. Kuner, J. Theis, and P.H. O'Farrell. 1985. Development of embryonic pattern in $D$. melanogaster as revealed by accumulation of the nuclear en protein. Cell 43: $59-69$.

DiNardo, S., E. Sher, J. Heemskerk-Jongens, J.A. Kassis, and P.H. O'Farrell. 1988. Two-tiered regulation of spatially patterned engrailed gene expression during Drosophila embryogenesis. Nature 332: 604-609.

Fjose, A., W.J. McGinnis, and W.J. Gehring. 1985. Isolation of a homoeo box-containing gene from the engrailed region of Drosophila and the partial distribution of its transcripts. Nature 313: 284-289.

Ghysen, A. and C. O'Kane. 1989. Neural enhancer-like elements as specific cell markers in Drosophila. Development 105: $35-52$.

Han, K., M.S. Levine, and J.L. Manley. 1989. Synergistic activation and repression of transcription by Drosophila homeobox proteins. Cell 56: 573-583.

Henikoff, S. 1984. Unidirectional digestion with exonuclease III creates targeted breakpoints for DNA sequencing. Gene 28: $351-359$.

Hiromi, Y., A. Kuroiwa, and W.J. Gehring. 1985. Control elements of the Drosophila segmentation gene fushi tarazu. Cell 43: 603-613.
Hooper, J.E. and M.P. Scott. 1989. The Drosophila ptc gene encodes a putative membrane protein required for segmental patterning. Cell 59: 751-765.

Howard, K. and P. Ingham. 1986. Regulatory interaction between the segmentation genes fushi tarazu, hairy and en grailed in the Drosophila blastoderm. Cell 44: 949-957.

Ingham, P.W. 1988. The molecular genetics of embryonic pattern formation in Drosophila. Nature 335: 25-34.

Jaynes, J.B. and P.H. O'Farrell. 1988. Activation and repression of transcription by homeo-domain containing proteins that bind a common site. Nature 336: 744-749.

Jürgens, G., E. Wieschaus, C. Nüsslein-Volhard, and H. Kluding. 1984. Mutations affecting the pattern of the larval cuticle in Drosophila melanogaster. II. Zygotic loci on the third chromosome. Wilhelm Roux's Arch. Dev. Biol. 193: 283-295.

Kassis, J.A., M.L. Wong, and P.H. O'Farrell. 1985. Electron microscopic heteroduplex mapping identifies regions of the engrailed locus that are conserved between Drosophila melanogaster and Drosophila virilis. Mol. Cell. Biol. 5: 36003609.

Kassis, J.A., S.J. Poole, D.K. Wright and P.H. O'Farrell. 1986. Sequence conservation in the protein coding and intron regions of the engrailed transcription unit. EMBO I. 5: 35833589.

Kassis, J.A., C. Desplan, D.K. Wright and P.H. O'Farrell. 1989. Evolutionary conservation of homeo-domain binding sites and other sequences upstream and within the major transcription unit of the Drosophila segmentation gene en. Mol. Cell. Biol. 9: 4304-4311.

Kornberg, T., I. Siden, P. O'Farrell, and M. Simon. 1985. The engrailed locus of Drosophila: In situ localization of transcripts reveals compartment-specific expression. Cell 40: 45-53.

Laughon, A. and M.P. Scott. 1984. Sequence of a Drosophila segmentation gene: protein structure homology with DNA binding proteins. Nature 310: $25-31$.

Martinez-Arias, A. and P.A. Lawrence. 1985. Parasegments and compartments in the Drosophila embryo. Nature 313: 639642.

Martinez-Arias, A., N.E. Baker, and P.W. Ingham. 1988. Role of segment polarity genes in the definition and maintenance of cell states in the Drosophila embryo. Development 103: $157-170$.

Nakano, Y., I. Guerrero, A. Hidalgo, A. Taylor, J.R.S. Whittle, and P.W. Ingham. 1989. A protein with several possible membrane-spanning domains encoded by the Drosophila segment polarity gene ptc. Nature 341: 508-513.

Nüsslein-Volhard, C. and E. Wieschaus. 1980. Mutations affecting segment number and polarity in Drosophila. Nature 287: $795-801$.

Nüsslein-Volhard, C., E. Wieschaus, and H. Kluding 1984. Mutations affecting the pattern of the larval cuticle in Drosophila melanogaster. I. Zygotic loci on the second chromosome. Wilhelm Roux's Arch. Dev. Biol. 193: 267-282.

O'Kane, C.J. and W.J. Gehring. 1987. Detection in situ of genomic regulatory elements in Drosophila. Proc. Natl. Acad. Sci. 84: 9123-9127.

Patel, N.H., E. Martin-Blanco, K.G. Coleman, S.J. Poole, M.C. Ellis, T.B. Kornberg, and C.S. Goodman. 1989. Expression of en proteins in arthropods, annelids, and chordates. Cell 58: 955-968.

Pirotta, V. 1988. Vectors for P-mediated transformation in Drosophila. In Vectors, A survey of molecular cloning vectors and their uses, (ed. R.L. Rodriguez and D.T. Denhardt), pp. 437-456. Butterworths, Boston. 
Rijsewijk, F., M. Schuermann, E. Wagenaar, P. Parren, D. Weigel, and R. Nusse. 1987. The Drosophila homolog of the mouse mannary oncogene int- 1 is identical to the segment polarity gene wingless. Cell 50: 649-657.

Robertson, H.M., C.R. Preston, R.W. Phillis, D.M. JohnsonSchlitz, W.K. Benz and W.R. Engels. 1988. A stable genomic source of $\mathrm{P}$ element transposase in Drosophila melanogaster. Genetics 118: 461-470.

Rubin, G.M. and A.C. Spradling. 1982. Genetic transformation of Drosophila with transposable element vectors. Science 218: $348-353$.

Soeller, W.C., S.J. Poole, and T. Kornberg. 1988. In vitro transcription of the Drosophila engrailed gene. Genes Dev. 2: $68-81$.

Tautz, D. and C. Pfeifle. 1989. A non-radioactive in situ hybridization method for the localization of specific RNAs in Drosophila embryos reveals a translational control of the segmentation gene hunchback. Chromosoma 98: 81-85.

Thummel, C.S., A.M. Boulet, and H.D. Lipshitz 1988. Vectors for Drosophila P-element-mediated transformation and tissue culture transfection. Gene 74: 445-456.

Weir, M.P., B.A. Edgar, T. Kornberg and G. Schubiger. 1988. Spatial regulation of engrailed expression in the Drosophila embryo. Genes Dev. 2: 1194-1203.

Wieschaus, E., C. Nüsslein-Volhard and G. Jürgens. 1984. Mutations affecting the pattern of the larval cuticle in Drosophila melanogaster. III. Zygotic loci on the $\mathrm{X}$ chromosome and fourth chromosome. Wilhelm Roux's Arch. Dev. Biol. 193: $267-282$. 


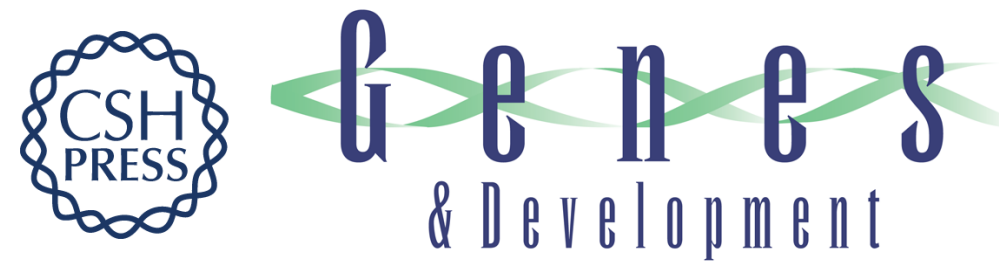

\title{
Spatial and temporal control elements of the Drosophila engrailed gene.
}

\author{
$\mathrm{J}$ A Kassis
}

Genes Dev. 1990, 4:

Access the most recent version at doi:10.1101/gad.4.3.433

$\begin{array}{ll}\text { References } & \begin{array}{l}\text { This article cites } 38 \text { articles, } 12 \text { of which can be accessed free at: } \\ \text { http://genesdev.cshlp.org/content/4/3/433.full.html\#ref-list-1 }\end{array}\end{array}$

License

Email Alerting

Service

Receive free email alerts when new articles cite this article - sign up in the box at the top right corner of the article or click here.

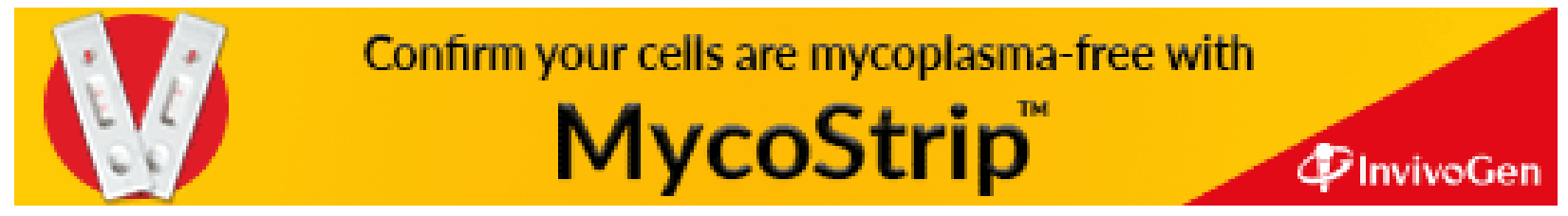

